\title{
Engelstrompeten ohne Erde aussähen
}

\author{
Neville Dearden
}

\begin{abstract}
As most gardeners know, damping off is a fungus that spreads across damp soil. Commercial growers have developed soil-less techniques for seed germination. Experiences with the germination of Brugmansia seeds in rock wool cubes are outlined.
\end{abstract}

\section{Zusammenfassung}

Der Pilz, der in Sämlingskulturen häufig zur Umfallkrankheit führt, kann sich leicht in feuchter Erde ausbreiten. Kommerzielle Pflanzenzüchter haben eine Methode entwickelt, Samen in erdfreien Kulturmedien zu keimen. Erfahrungen mit der Keimung von Brugmansia-Samen in Steinwolle-Würfeln werden dargestellt.

1. Warum überhaupt Kultur in einem erdfreien Substrat?

In Gärtnerkreisen ist es bekannt, dass PflanzenKeimlinge leicht von der so genannten Umfallkrankheit befallen werden können. Der für diese Schäden verantwortliche Pilz kann sich in feuchter Erde gut ausbreiten und die Jungpflanzen infizieren. Kommerzielle Pflanzenzüchter laufen dabei Gefahr, durch Verlust ihrer kompletten Sämlingskulturen erheblichen finanziellen Schaden zu erleiden. Es wurden deshalb Methoden entwickelt, die Sämlinge diverser Arten unter sterilen Bedingungen ohne Erde, z. B. in Glas- oder Steinwolle, heranzuziehen. Eine ganze Reihe empfindlicher Arten lässt sich auf diese Art und Weise (vor allem in Steinwolle) erfolgreicher als in Erde aussähen. Diese Ergebnisse motivierten auch mich, diese Ver-

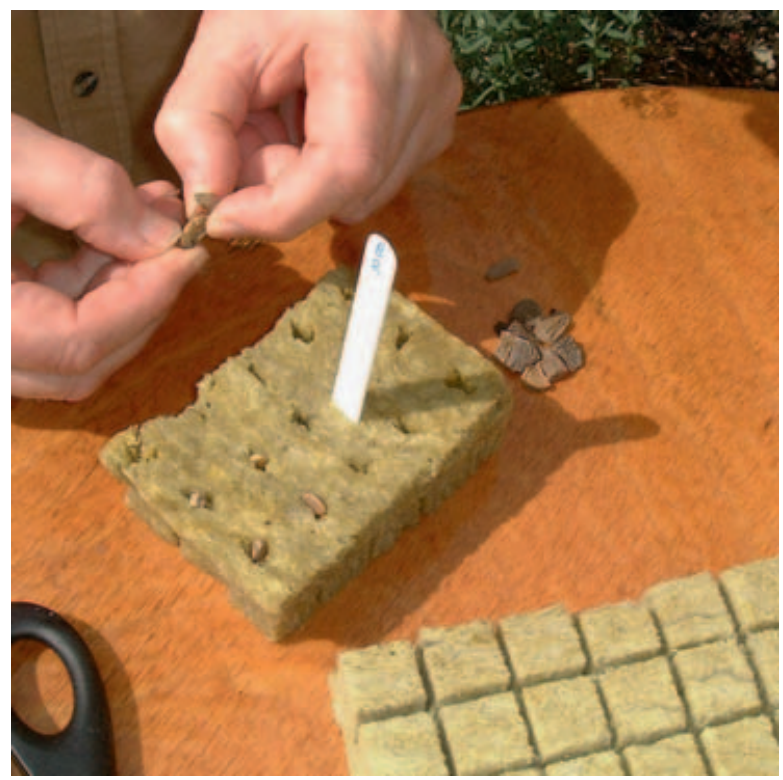

mehrungsmethode an Brugmansien auszuprobieren.

\section{Benötigte Materialien}

Eine Aussaat von Samen ohne Erde in Mineralwolle ist sehr einfach. Wichtig für einen Erfolg ist allerdings, dass die Sauberkeit der Kulturen kontinuierlich gewährleistet ist. Für die Aussaat werden Blöcke aus Steinwolle, die in viele kleine Würfel unterteilt sind, verwendet. Diese oder auch einzelne Würfel sind in Fachgeschäften für Gärtnereibedarf erhältlich oder über das Internet zu beziehen. Wichtig ist, Blöcke mit möglichst kleinen Würfeln zu verwenden, damit beim späteren Umsetzen der Keimlinge in Töpfe mit Erde (s. u.) nicht zu viel Steinwolle übertragen wird. Ich verwende SteinwolleWürfel, die eine Kantenlänge von knapp $2 \mathrm{~cm}$ haben. Natürlich kann man ungeteilte Steinwolle-Blöcke auch selbst in Würfel individueller Größe zuschneiden. Diese lässt sich mit einer Schere oder scharfen Klinge gut zer- bzw. einschneiden. Es versteht sich von selbst, nur Samen einer einzigen Sorte in einem bestimmten Bereich des Blockes auszusähen und zu etikettieren.

Für jeden Samen wird ein eigener Würfel verwendet. Eine saubere Kunststoff-Wanne mit reinem Wasser wird zum Wässern der Steinwolle benutzt.

Abb. 1: Die Samen werden in Schlitze in den SteinwolleWürfeln gesteckt. Vorne ein Steinwolle-Block, der aus vielen Würfeln besteht. 


\section{Feuchtigkeit des Substrats}

Brugmansia-Samen keimen nur bei ausreichender Wärme, guter Belüftung und hoher Feuchtigkeit des Bodens. Steinwolle kann diese Anforderungen gut erfüllen. Denn sie isoliert sehr effektiv und schützt die Samen vor kurzzeitig auftretenden extremen Temperaturen. Da es sich um ein sehr poröses Material handelt, erlaubt es zudem eine gute Durchlüftung. Bei Zugabe von Wasser wird die Luft schnell aus den Poren verdrängt, sodass es Samen und Keimlingen sofort zur Verfügung steht. $\mathrm{Zu}$ viel sowie zu wenig Wasser würde den Samen schaden. Ein weiterer Vorteil von Steinwolle besteht darin, dass sie beständig gegenüber Schimmel, Fäulnis und Ungeziefer ist.

Um eine zufriedenstellende Durchfeuchtung des Kulturmediums zu erhalten, wird der Steinwolle-Block bis zur Hälfte in eine Kunststoffwanne mit sauberem Wasser gesetzt. Bei Zweifeln an der Wasserqualität ist abgekochtes oder destilliertes Wasser zu verwenden. Anschließend erfolgt ein sorgfältiges Zusammendrücken der Würfel. Die Steinwolle wird dabei parallel zur Faserrichtung auf $3 / 4$ ihres Originalvolumens komprimiert.

\section{Aussaat}

Mit dem Fingernagel werden gegebenenfalls an den Samen anhaftende Fruchtreste entfernt. Anschließend werden die Samen in Schlitze, die in die Steinwolle hineingeschnitten wurden, geschoben. Mit Hilfe eines stumpfen hölzernen Cocktailspießes können die Samen leicht in das Kulturmedium gedrückt und in die richtige Position gebracht werden. Bei diesem Arbeitsschritt verliert ein zuvor optimal befeuchteter Steinwolle-Block bei der Ausübung von Druck kein Wasser. Mit Hilfe eines feinen Sprühers wird dann anschließend die Steinwolle von oben mit Wasser besprüht. Einmal ausgesät,

Abb. 2 (oben): Etikettierte und mit Samen bestückte Steinwolle-Würfel in einer Kunststoffwanne.

Abb. 3 (Mitte): Keimlinge im Steinwolle-Substrat.

Abb. 4 (unten): In Erde umgesetzte Keimlinge.
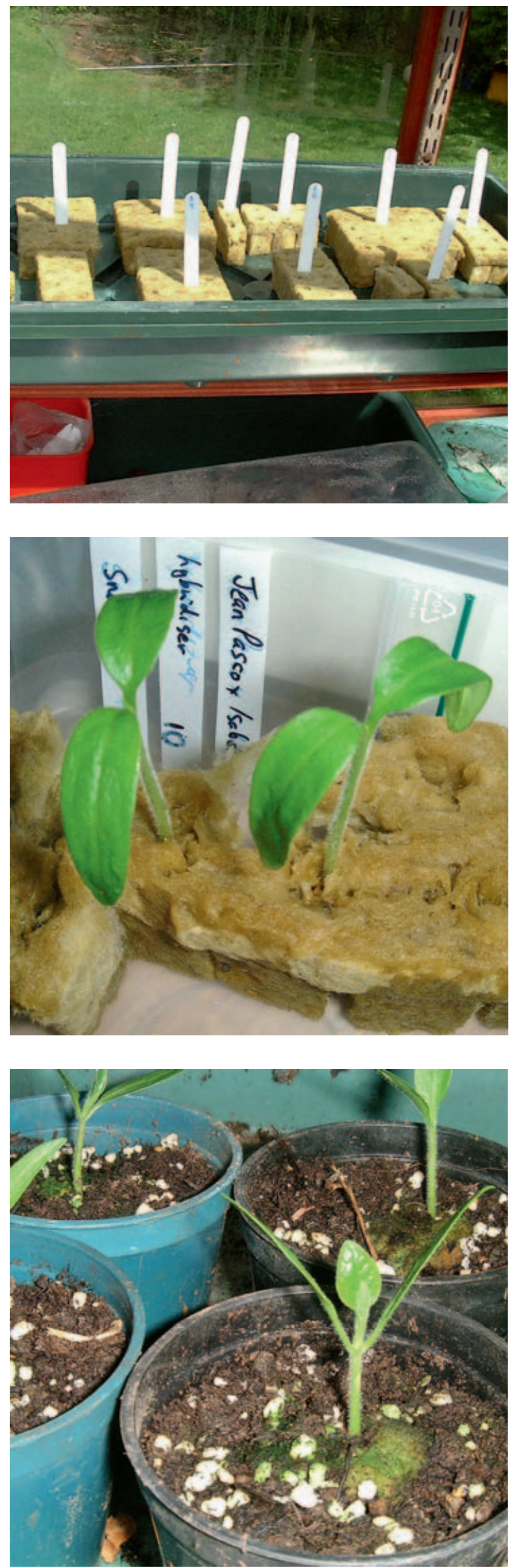